\title{
Enabling demand generation for $7.1 \%$ chlorhexidine for umbilical cord care in Togo
}

Patricia S Coffey, PhD, $\mathrm{MPH}^{1}$ @ , Alhi Nguessan, $\mathrm{MBA}^{2}$, Abram Amétépé Agossou, MD, Pédiatre, MPH ${ }^{3}$, Basilia Coefe Nitiema, MD, MPH ${ }^{4}$

1 PATH Medical Devices and Health Technologies, 2201 Westlake Ave, Suite 200, Seattle, WA, USA, 98211, 2 EMC- Etudes de Marché et Conseils, Avenue Dr Crozet, Immeuble XL 01 BP 7005 Abidjan 01, Cote d'Ivoire, ${ }^{3}$ Directeur de la Santé de la Mère et de l'Enfant, Ministry of Health, Lomé, Togo,

4 Independent Consultant, 01 BP 745 Ouagadougou 01, Ouagadougou, Burkina Faso

Keywords: product pricing, women, togo, demand generation, newborn, umbilical cord care

https://doi.org/10.29392/001c.18655

\section{Journal of Global Health Reports}

Vol. 4, 2020

\section{Background}

A novel newborn umbilical cord care product, $7.1 \%$ chlorhexidine digluconate, which delivers $4 \%$ free chlorhexidine (CHX), is being introduced in Togo. Although the policy framework for this product introduction has been in place since 2017, product use appears to be limited. The overall aim of this mixed methods study was to understand how to generate demand for an umbilical cord care product among (i) pregnant women and/or women who recently birthed and (ii) providers in Togo. The specific study objectives were to understand current cord care practices and identify willingness and rationale to use CHX and preferred product pricing and source.

\section{Methods}

We collected data in December 2019 via 13 focus group discussions (FGDs) with 60 pregnant women and 38 women who recently birthed and through semi-structured interviews with 39 providers in 13 randomly selected facilities that provide essential newborn care services in all six regions of the country.

\section{Results}

Most of the FGD participants were unaware of this novel cord care product. FGD participants reported high hypothetical acceptability of the product due to its aesthetic presentation, ease of use, ease of storage, and provider recommendation. Actual use was contingent on positive product performance in terms of time to heal the wound, fast cord separation, and absence of pain in the infant. Almost $70 \%$ of the providers were aware of $\mathrm{CHX}$ and all of them were supportive of its use. Because CHX availability was very limited in-country, providers recommended alcohol or other skin disinfectants for cord cleaning. Both FGD participants and providers viewed the effect of CHX use on time to cord separation as a key determinant of product uptake. Pricing of FCFA 500-800 was considered affordable for most families.

\section{Conclusions}

To generate demand, providers could prescribe CHX as an essential item at the time of delivery. The CHX product should be available for sale at pharmacies and health facilities as a key component of an integrated birthing kit. A tiered pricing strategy could extend coverage to both facility-based and home-based births.

Global efforts are currently underway to introduce and scale a potentially lifesaving product for newborn umbilical cord care. ${ }^{1}$ This product, $7.1 \%$ chlorhexidine digluconate, which delivers $4 \%$ free chlorhexidine (CHX), is topically applied to the newly cut umbilical cord to prevent neonatal infection. The product comes in a liquid or gel formulation. Published data support the use of CHX for cord cleaning as a feasible, acceptable, efficacious, safe, and cost-effective intervention to reduce neonatal mortality in settings with high neonatal mortality and poor hygiene. ${ }^{2-7}$

In Togo, the policy framework to introduce and scale CHX is in place. A gel product containing $7.1 \%$ chlorhexidine for umbilical cord care was added to the national essential medicines list in 2017. Also in 2017, CHX was included in the revised Ministry of Health ( $\mathrm{MOH})$ Standards and Protocols Policy documents. Use of CHX is taught in training schools and in continuing education as part of the essential newborn care package. In 2018, the MOH prepared 
a memo giving instructions on the use of CHX gel for the care of the umbilical cord in newborns and disseminated it to all public-sector facilities offering essential newborn care services. In practice, however, CHX is used often in the private sector and less often in the public sector, which still relies on alcohol for umbilical cord care. Families often use traditional substances or dry cord care. The $\mathrm{MOH}$ is unable to include the purchase of this commodity in its annual budget, so families will need to purchase it as part of their birth preparations. The $\mathrm{MOH}$ is very concerned that the price point for the CHX product is affordable for families. Strengthening demand generation will link public-sector programming with a newborn commodity that is available through the private sector.

The overall aim of this study was to understand how to generate demand for an umbilical cord care product among (1) pregnant women and/or women who recently birthed and (2) providers in Togo. The specific study objectives were to understand current cord care practices and identify willingness and rationale to use CHX and preferred product pricing and source. Understanding the optimal manner to generate demand for this umbilical cord care product will assist the $\mathrm{MOH}$ and others to develop relevant strategies for its introduction and uptake.

\section{METHODS}

In this observational cross-sectional, mixed methods exploratory study, we collected information via focus group discussions (FGDs) with pregnant women and/or women who recently birthed (within the last 12 months) and via semi-structured interviews with providers. The FGDs and provider interviews took place during antenatal care days at 12 facilities (2 facilities per region) and one main referral hospital in Lomé that provide essential newborn care services. There are a total of 43 basic emergency obstetric care (SONU B) and 24 comprehensive emergency obstetric care (SONU C) facilities in the country. In each of the six regions in Togo, we randomly selected one SONU B and one SONU $\mathrm{C}$ facility from all facilities that offer essential newborn care services in the selected region (Figure 1). Six facilities offer basic emergency obstetric care (SONU B) and seven facilities offer comprehensive emergency obstetric care (SONU C) services. Three facilities including the main referral hospital were in the urban and peri-urban area of the capital, Lomé.

\section{STUDY POPULATION}

We did not calculate sample size for this study; the number of participants was decided based on our initial hypothesis and budget limitations as is appropriate for a small, exploratory effort. The participants were selected by convenience sampling. Pregnant women and/or women who have birthed recently (within the last 12 months) and who were waiting for an antenatal care or postnatal care visit on the day the research team visited were asked to participate in the FGD. Providers that were on duty in the selected facilities on the day the research team visited were asked to participate in an interview.

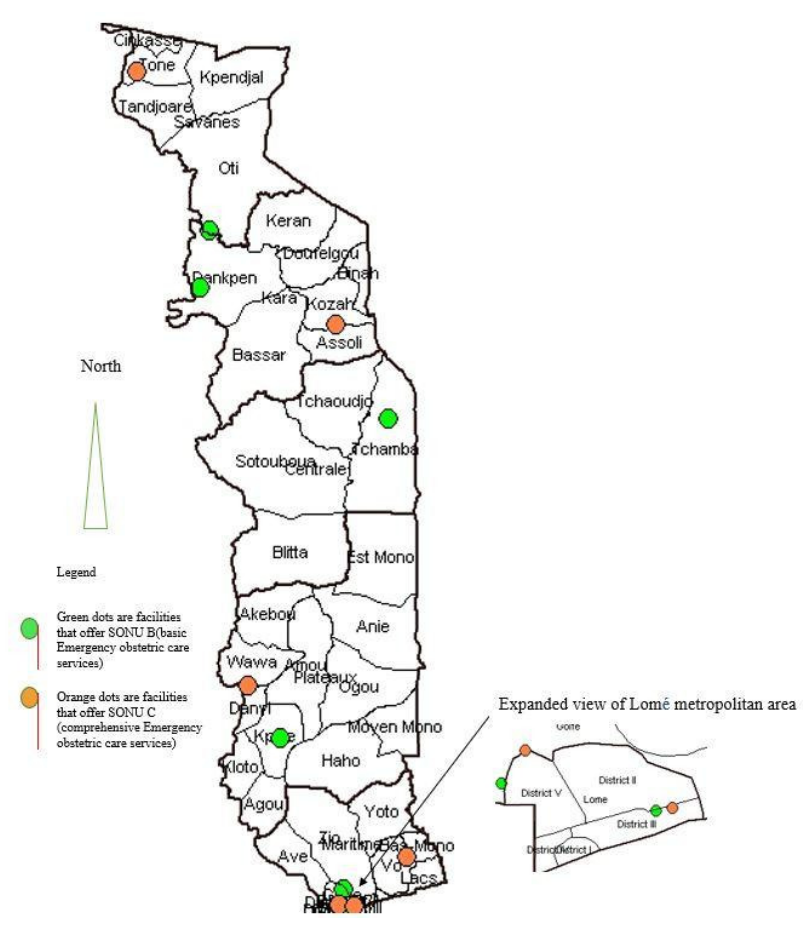

Figure 1. Map of facilities randomly allocated to study sample $(n=13)$.

The following inclusion and exclusion criteria were applied in this study.

Inclusion:

- 18 years of age or older (all).

- Be a pregnant woman or a woman who birthed within the last 12 months (FGD participants only).

- Be currently providing maternal newborn clinical services at the selected health facility (providers only).

- Agree to be tape-recorded to be in the FGDs (women only).

\section{Exclusion:}

- Not a pregnant woman or a woman who birthed within the last 12 months who is attending antenatal care visit or postnatal care visit at the selected facility.

- Provider not currently providing antenatal care or postnatal care services at the selected health facility.

A letter from the $\mathrm{MOH}$ was provided to each facility in advance of the study initiation. To prepare for the data collection, the research team identified the day of the week that antenatal care and/or postnatal care is conducted at the selected facility. The research team visited the facility on the day of the week that antenatal care or postnatal care was offered. At least one provider that offered these services at the selected facility was interviewed. Pregnant women or women who birthed within the last 12 months who were waiting to attend antenatal care or postnatal care services were asked if they were willing and interested to participate in the FGD.

We obtained oral consent from the FGD participants and the providers who were interviewed. The consent form was read in French or Ewe. Potential study participants agreed 
Table 1. Composition of FGDs $(n=13)$.

\begin{tabular}{|c|c|c|c|}
\hline Health center & $\begin{array}{l}\text { Number of } \\
\text { participants }\end{array}$ & $\begin{array}{c}\text { Pregnant } \\
\text { women }\end{array}$ & $\begin{array}{l}\text { Women who birthed within last } 12 \\
\text { months }\end{array}$ \\
\hline Centre Hospitalier Secondaire de Bé & 8 & 4 & 4 \\
\hline Centre Médico Scolaire de Gbényédji & 6 & 6 & 0 \\
\hline $\begin{array}{l}\text { Centre Hospitalier Universitaire Sylvanus } \\
\text { Olympio }\end{array}$ & 7 & 4 & 3 \\
\hline $\begin{array}{c}\text { Unité de Soins Périphérique de Agoé } \\
\text { Elavagno }\end{array}$ & 7 & 6 & 1 \\
\hline Centre Hospitalier Préfectoral de Vogan & 6 & 1 & 5 \\
\hline Centre Médico Scolaire d'Adéta & 8 & 3 & 5 \\
\hline Centre Hospitalier Préfectoral de Badou & 9 & 6 & 3 \\
\hline Centre Médico Scolaire de Bago & 8 & 5 & 3 \\
\hline $\begin{array}{c}\text { Centre Hospitalier Préfectoral de } \\
\text { Sotouboua }\end{array}$ & 6 & 2 & 4 \\
\hline $\begin{array}{l}\text { Centre Hospitalier Préfectoral de Guérin } \\
\text { Kouka }\end{array}$ & 9 & 2 & 7 \\
\hline Centre Hospitalier Régional de Kara & 8 & 6 & 2 \\
\hline Centre Médico Scolaire de Barkoissi & 8 & 8 & 0 \\
\hline Centre Hospitalier Régional de Dapaong & 8 & 7 & 1 \\
\hline TOTAL & 98 & 60 & 38 \\
\hline
\end{tabular}

verbally to the informed consent document prior to any study-related assessments or procedures. They were given the opportunity to think about it prior to agreeing to participate. The informed consent document was given to study participants for their records if they desired one. Participant approval of oral consent was tracked in an oral consent log. FGD participants received refreshments and a snack. We did not provide any compensation to providers.

The research team carrying out the FGDs and interviews consisted of four researchers, all of whom had advanced masters-level degrees and prior experience conducting field research. The two FGD facilitators were women. All interviews and FGDs were conducted in French or in Ewe, depending on the participant language of choice. In both the interviews and the FGDs, the research team explained and showed a sample of the CHX gel product to allow the study participant to provide real-time feedback on the test and its potential suitability for use.

The FGDs were audio-recorded, and one member of the research team also took notes manually. The audio files were transcribed, and the textual data were entered into a database using Microsoft Word and analyzed for thematic content. To analyze the qualitative data, we employed reflexive thematic analysis with an inductive approach whereby coding and theme development are directed by the content of the data.

Quantitative data were entered into a database in Microsoft Excel, which was used to calculate frequencies, proportions and measures of central tendency. This market research was approved by the Comité de Bioéthique pour la Recherche en Santé (CBRS) at the Togo Ministry of Health in October 2019.

\section{RESULTS}

During December 2019, we conducted 13 FGDs (1 per facility) with 60 pregnant women and 38 women who recently birthed and interviews with three providers at each facility $(\mathrm{n}=39)$.

\section{FOCUS GROUP DISCUSSIONS}

Table 1 displays the composition of the 13 FGDs. Almost two-thirds of the 98 participants were pregnant women and the remainder were women who had birthed within last 12 months.

The demographic characteristics of the women in the FGDs are displayed in Table 2. Respondent ages ranged from 19 to 36 years and their reported monthly income ranged from FCFA 10,000-80,000. Almost half of the women (48\%) stated their profession as being in sales while only ten percent of women reported being farmers. Other professions mentioned were hairdresser, tailor, teacher, manager, secretary, civil servant, accountant, maintenance worker, businesswoman, non-governmental organization staff, student and homemaker.

The demographic characteristics of the providers are displayed in Table 3 . The providers reported a wide range of years of professional experience ranging from less than 1 year to 29 years $(M=13.3, S D=7.3$, median=8). Provider work experience at the facility where they were interviewed ranged from 2 months to 28 years $(\mathrm{M}=6.75$ years, $\mathrm{SD}=7.15$ years, median $=4$ years).

Providers reported that, on average, 119 births were managed ( $\mathrm{SD}=201.0$, median-55) and 178 women receive antenatal care $(\mathrm{SD}=312.8$, median $=100)$ at the 13 facilities 
Table 2. Demographic characteristics of FGD participants, by facility $(n=98)$.

\begin{tabular}{|c|c|c|c|c|c|c|}
\hline \multirow[t]{2}{*}{ Health center } & \multirow{2}{*}{$\begin{array}{l}\text { Age mean } \\
\text { (SD) in } \\
\text { years }\end{array}$} & \multicolumn{4}{|c|}{ Educational level attained ( $\mathrm{n}$ ) } & \multirow{2}{*}{$\begin{array}{c}\text { Monthly income } \\
\text { Mean (SD) in } \\
\text { FCFA }\end{array}$} \\
\hline & & None & Primary & Secondary & University & \\
\hline $\begin{array}{l}\text { Centre Hospitalier } \\
\text { Secondaire de Bé }(n=8)\end{array}$ & $\begin{array}{c}26 \\
(9.18)\end{array}$ & 0 & 4 & 3 & 1 & $\begin{array}{c}32625 \\
(20028.11)\end{array}$ \\
\hline $\begin{array}{l}\text { Centre Médico Scolaire de } \\
\text { Gbényédji }(n=6)\end{array}$ & $\begin{array}{c}27 \\
(3.72)\end{array}$ & 2 & 1 & 2 & 1 & $\begin{array}{c}33000 \\
(16431.68)\end{array}$ \\
\hline $\begin{array}{l}\text { Centre Hospitalier } \\
\text { Universitaire Sylvanus } \\
\text { Olympio }(n=7)\end{array}$ & $\begin{array}{c}30 \\
(2.69)\end{array}$ & 0 & 1 & 4 & 2 & $\begin{array}{l}73571.43 \\
(45158.45)\end{array}$ \\
\hline $\begin{array}{l}\text { Unité de Soins Périphérique } \\
\text { de Agoé Elavagno }(n=7)\end{array}$ & $\begin{array}{c}25 \\
(3.59)\end{array}$ & 0 & 1 & 4 & 2 & $\begin{array}{l}43571.43 \\
(8997.354)\end{array}$ \\
\hline $\begin{array}{l}\text { Centre Hospitalier } \\
\text { Préfectoral de Vogan }(n=6)\end{array}$ & $\begin{array}{c}25 \\
(4.96)\end{array}$ & 3 & 2 & 1 & 0 & $\begin{array}{c}19666.67 \\
(7118.052)\end{array}$ \\
\hline $\begin{array}{l}\text { Centre Médico Scolaire } \\
\text { d'Adéta }(n=8)\end{array}$ & $\begin{array}{c}26 \\
(3.92)\end{array}$ & 1 & 6 & 1 & 0 & $\begin{array}{c}22250 \\
(7206.148)\end{array}$ \\
\hline $\begin{array}{l}\text { Centre Hospitalier } \\
\text { Préfectoral de Badou ( } n=9)\end{array}$ & $\begin{array}{l}24.55556 \\
(3.64)\end{array}$ & 5 & 2 & 2 & 0 & $\begin{array}{l}25666.67 \\
(7533.26)\end{array}$ \\
\hline $\begin{array}{l}\text { Centre Médico Scolaire de } \\
\text { Bago }(n=8)\end{array}$ & $\begin{array}{c}28 \\
(5.700877)\end{array}$ & 6 & 2 & 0 & 0 & $\begin{array}{c}10000 \\
(2976.095)\end{array}$ \\
\hline $\begin{array}{l}\text { Centre Hospitalier } \\
\text { Préfectoral de Sotouboua } \\
(n=6)\end{array}$ & $\begin{array}{c}27 \\
(5.230)\end{array}$ & 0 & 5 & 1 & 0 & $\begin{array}{c}31333.33 \\
(14375.91)\end{array}$ \\
\hline $\begin{array}{l}\text { Centre Hospitalier } \\
\text { Préfectoral de Guérin Kouka } \\
(n=9)\end{array}$ & $\begin{array}{c}27 \\
(4.47)\end{array}$ & 0 & 7 & 2 & 0 & $\begin{array}{c}33222.22 \\
(11410.28)\end{array}$ \\
\hline $\begin{array}{l}\text { Centre Hospitalier Régional } \\
\text { de Kara }(n=8)\end{array}$ & $\begin{array}{c}25 \\
(5.38)\end{array}$ & 0 & 6 & 1 & 1 & $\begin{array}{c}36875 \\
(13611.31)\end{array}$ \\
\hline $\begin{array}{l}\text { Centre Médico Scolaire de } \\
\text { Barkoissi }(n=8)\end{array}$ & $\begin{array}{c}30 \\
(2.61)\end{array}$ & 4 & 4 & 0 & 0 & $\begin{array}{c}21375 \\
(4897.157)\end{array}$ \\
\hline $\begin{array}{l}\text { Centre Hospitalier Régional } \\
\text { de Dapaong }(n=8)\end{array}$ & $\begin{array}{c}28 \\
(3.33)\end{array}$ & 2 & 2 & 3 & 1 & $\begin{array}{c}38750 \\
(14577.38)\end{array}$ \\
\hline TOTAL & $\begin{array}{c}26.7 \\
(4.23)\end{array}$ & 23 & 43 & 24 & 8 & \\
\hline
\end{tabular}

each month. Of the 31 providers who responded, almost all reported that women attend an average of four antenatal care visits (one provider each reported an average of five, six and nine visits). All 31 providers reported that women usually register and receive their first antenatal care visit in the second trimester (except two who reported the first trimester) and their last antenatal care visit in the third trimester. In general, the 31 providers considered that antenatal care attendance was highest in the second trimester except for two who said the third trimester.

\section{BIRTH PREPARATION AND CORD CARE PRACTICES}

Both the FGD participants and providers agreed that a variety of items either for the pregnant woman or the newborn are requested or recommended for childbirth. The type and number of items cited by both groups were generally similar except for some personal grooming supplies identified by the women and the providers who identified the need to bring or purchase a birth kit (Table 4).

The composition of the birth kits as well as the price can vary from one health center to another. The price of kits offered by health centers in this study ranged from 4,000 to 10,050 FCFA. The birth kits that are available from health centers usually focus on medical supplies only. For example, the kit offered by the Agoé Elavagnon health center includes sterile gloves, supplies for intravenous infusion, oxytocin, vitamins, scalpel blade, cord clamp, and CHX gel. In some health centers, a list of items necessary for childbirth is available, although generally the providers dictate the list verbally rather than give the pregnant women a printed list.

All FGD participants agreed that the necessary items (see Table 4) are available at the pharmacy, at the seller in front of the health centers, and at the market. The FGD participants also said that they learn about the things they need from new mothers or older women in their families and from medical staff. Participants estimated that the cost of these items ranged from FCFA 20,000 to FCFA 150,000, with the majority between FCFA 35,000 and 50,000. Any adult person in the family may purchase the kit, including the pregnant woman or her husband, mother, mother-in-law, or sister-in-law. 
Table 3. Demographic characteristics of providers, by facility $(n=39)$.

\begin{tabular}{|c|c|c|c|}
\hline Name of facility & Profession & $\begin{array}{l}\text { Years of professional } \\
\text { experience }\end{array}$ & $\begin{array}{l}\text { Years at the } \\
\text { facility }\end{array}$ \\
\hline \multirow{3}{*}{ Centre Hospitalier Secondaire de Bé } & Midwife (supervisor) & 25 years & 18 years \\
\hline & $\begin{array}{l}\text { Resuscitation anesthesiologist } \\
\text { (general supervisor) }\end{array}$ & 29 years & 19 years \\
\hline & Midwife (responsible for labor ward) & 15 years & 14 years \\
\hline \multirow{3}{*}{ Centre Médico Scolaire de Gbényédji } & $\begin{array}{l}\text { Medical assistant (sanitation } \\
\text { engineer) }\end{array}$ & 9 years & 2 months \\
\hline & Midwife (responsible CPN) & 6 years & 6 years \\
\hline & Midwife (maternity manager) & 11 years & 3 years \\
\hline \multirow{3}{*}{$\begin{array}{l}\text { Centre Hospitalier Universitaire } \\
\text { Sylvanus Olympio }\end{array}$} & Neonatal pediatrician & 10 years & 4 years \\
\hline & $\begin{array}{l}\text { Medical assistant (pediatrics } \\
\text { supervisor) }\end{array}$ & 11 years & 11 years \\
\hline & Midwife (maternity supervisor ) & 12 years & 11 years \\
\hline \multirow{3}{*}{$\begin{array}{l}\text { Unité de Soins Périphérique de Agoé } \\
\text { Elavagno }\end{array}$} & Midwife (maternity supervisor) & 19 years & 10 months \\
\hline & Medical assistant (superintendent) & 11 years & 2 months \\
\hline & Midwife (responsible for PTME) & 11 years & 2 years \\
\hline \multirow{3}{*}{$\begin{array}{l}\text { Centre Hospitalier Préfectoral de } \\
\text { Vogan }\end{array}$} & Midwife (birth attendant) & 3 years & 3 months \\
\hline & Midwife (maternity supervisor) & 12 years & 3 years \\
\hline & Medical assistant & 7 years & 3 months \\
\hline \multirow{3}{*}{ Centre Médico Scolaire d'Adéta } & Orderly nurse & 19 years & 4 months \\
\hline & Birth attendant & 10 years & 4 years \\
\hline & Midwife (maternity manager) & 6 years & 5 years \\
\hline \multirow{3}{*}{$\begin{array}{l}\text { Centre Hospitalier Préfectoral (CHP) } \\
\text { de Badou }\end{array}$} & Surgeon (director of CHP) & 17 years & 2 years \\
\hline & Midwife (deputy manager) & 8 years & 3 months \\
\hline & Midwife & 2 years & 3 months \\
\hline \multirow{3}{*}{ Centre Médico Scolaire de Bago } & Midwife (maternity manager) & 9 months & 3 months \\
\hline & Hygiene assistant (vaccine manager) & 8 years & 2 years \\
\hline & Permanent birth attendant & 30 years & 28 years \\
\hline \multirow{3}{*}{$\begin{array}{l}\text { Centre Hospitalier Préfectoral de } \\
\text { Sotouboua }\end{array}$} & Midwife (maternity manager) & 26 years & 12 years \\
\hline & Birth attendant & 21 years & 4 years \\
\hline & Midwife assistant & 11 years & 4 years \\
\hline \multirow{3}{*}{$\begin{array}{l}\text { Centre Hospitalier Préfectoral de } \\
\text { Guérin Kouka }\end{array}$} & $\begin{array}{l}\text { Midwife (point person for } \\
\text { reproductive health }\end{array}$ & 9 years & 6 years \\
\hline & Permanent birth attendant & 23 years & 23 years \\
\hline & Permanent birth attendant & 21 years & 10 years \\
\hline \multirow{3}{*}{ Centre Hospitalier Régional de Kara } & Midwife & 7 years & 4 months \\
\hline & Midwife & 14 years & 14 years \\
\hline & Midwife & 11 years & 3 years \\
\hline \multirow{3}{*}{ Centre Médico Scolaire de Barkoissi } & Health technician (center manager) & 8 years & 1 year \\
\hline & Midwife (maternity manager) & 10 years & 5 years \\
\hline & Permanent birth attendant (matron) & 18 years & 8 years \\
\hline \multirow{3}{*}{$\begin{array}{l}\text { Centre Hospitalier Régional de } \\
\text { Dapaong }\end{array}$} & Midwife (responsible for CPM) & 25 years & 19 years \\
\hline & Midwife & 6 years & 2 years \\
\hline & Midwife & 5 years & 2 years \\
\hline
\end{tabular}

Cutting the umbilical cord and subsequent care depends on the place of delivery. In maternity hospitals and health centers, the cut is made using a pair of scissors. FGD partic- ipants noted that they had heard stories from their mothers or grandmothers or other acquaintances that traditional birth attendants use various things, including a: 
- Razor blade.

- Glass bottle shard (the birth attendant breaks a bottle and selects a shard to use).

- Millet stem (birth attendant rubs the stalk against the wall to make it sharp to cut the cord).

- Special knife (used only for cutting the cord at each delivery).

- Palm branch (birth attendant cuts the branch at an angle to have a sharp edge).

- Pair of scissors.

FGD participants noted various substances that were used to support cord separation and healing. They mentioned shea butter, coconut or palm kernel oil, mouse excrement, hot water, cloves, pebbles, salt, crushed insects, plant sap, mixture of salt and sand, mixture of chalk and salt, Maggi cube (cooking broth), Close-Up toothpaste, chalk, table butter, and a mixture of butter and salt. The FGD participants further noted that these kinds of substances are used by traditional birth attendants for home births occurring in the villages or poor districts of the cities. All the pregnant FGD participants responded that they are planning to birth in the health center and follow provider recommendations about how to care for the umbilical cord of their newborns. FGD participants who had already birthed at the health centers discussed their general satisfaction with the use of alcohol and other products recommended by the providers because the cord separated relatively quickly (3-5 days after birth).

The FGD participants emphasized that it is important for the umbilical cord to fall off quickly and that many of these traditional substances facilitate cord separation, as noted:

"Yes. Butter and salt, you put it in the morning midday evening it falls quickly." [FGD 4]

\section{"Me personally, they put on toothpaste and the thing fell quickly. This is the petrolatum ointment that I took to put all around. This is the toothpaste there." [FGD 10]}

They also discussed information they had received from the health center regarding cord care. In general, the FGD participants reported that they use rubbing alcohol, petroleum jelly, Betadine (povidone-iodine), penicillin, CHX gel, or some mix of these treatments, as described below:

"We were told to clean with alcohol, alcohol in cotton to clean. But then I put petroleum jelly on it.”[FGD 1]

"Me too, it's Betadine because the doctor told me to use Betadine during my first consultation, so Betadine is what I intend to use.”[FGD 4]

"This is the petrolatum ointment that I took to put all around.”[FGD 13]

"Me, this is the alcohol we take, we clean everything around until it falls.” [FGD 6]

"I used simple petroleum jelly and when $t$ fell it was penicillin ointment that I was using." [FGD 1]

Once the umbilical cord has separated, the FGD participants explained the follow-up care:
Table 4. Free listing of items needed to prepare for childbirth, by women and providers.

\begin{tabular}{|c|c|c|}
\hline Item cited & $\begin{array}{l}\text { FGD } \\
\text { participants }\end{array}$ & Providers \\
\hline Clean pagnes & $\sqrt{ }$ & $\sqrt{ }$ \\
\hline Old pagnes* & $\sqrt{ }$ & $\sqrt{ }$ \\
\hline Bleach** & $\sqrt{ }$ & $\sqrt{ }$ \\
\hline Utensils & $\sqrt{ }$ & \\
\hline Perfume & $\sqrt{ }$ & \\
\hline Powders for the newborn & $\sqrt{ }$ & \\
\hline $\begin{array}{l}\text { Sponges for washing the } \\
\text { newborn }\end{array}$ & $\sqrt{ }$ & \\
\hline $\begin{array}{l}\text { Ointment for the } \\
\text { newborn }\end{array}$ & $\sqrt{ }$ & \\
\hline Petroleum jelly & $\sqrt{ }$ & $\sqrt{ }$ \\
\hline $\begin{array}{l}\text { Diapers and newborn } \\
\text { clothes }\end{array}$ & $\sqrt{ }$ & $\sqrt{ }$ \\
\hline Disinfectant** & $\sqrt{ }$ & $\sqrt{ }$ \\
\hline $\begin{array}{l}\text { Cotton to apply the } \\
\text { alcohol to cord }\end{array}$ & $\sqrt{ }$ & $\sqrt{ }$ \\
\hline $\begin{array}{l}\text { Alcohol for umbilical cord } \\
\text { care }\end{array}$ & $\sqrt{ }$ & $\sqrt{ }$ \\
\hline Detergent soap*** & $\sqrt{ }$ & $\sqrt{ }$ \\
\hline Bucket for taking bath & $\sqrt{ }$ & $\sqrt{ }$ \\
\hline $\begin{array}{l}\text { Basin to collect the } \\
\text { placenta }\end{array}$ & $\sqrt{ }$ & $\sqrt{ }$ \\
\hline Notebook & & $\sqrt{ }$ \\
\hline Night pot & & $\sqrt{ }$ \\
\hline $\begin{array}{l}\text { Birth kit or money to } \\
\text { purchase one }\end{array}$ & & $\sqrt{ }$ \\
\hline
\end{tabular}

"Old pagnes are used to cover the woman during childbirth and to soak up blood and wrap the placenta.

**FGD participants mentioned bleach to disinfect the birthing room and equipment. Providers mentioned Dettol (Reckitt Benckiser, UK) by brand name, used to disinfect the birthing table and room.

****FD participants mentioned Omo washing powder (Unilever, South Africa) or Mar seille soap (a traditional hard soap made from vegetable oils) for washing clothes and other items soiled during childbirth.

"And when it fell, that's it. I take pagne to put on the fire, and when it is hot, that's what I put on the cord." [FGD 12]

"There are others who put stones in the fire, when it's hot they take a pagne that they put on the pebble and then apply it to the cord." [FGD 3]

"I don't put anything, I leave in the open air when I leave the hospital, up to 6 days, that healed." [FGD 3]

In general, providers recommended that the umbilical cord be cared for with pharmaceutical products such as alcohol, Betadine (povidone-iodine), or Dermobacter lotion, which is a topical antiseptic lotion that contains a mixture benzalkonium chloride $5 \mathrm{gm}$ and chlorhexidine digluconate $0.2 \mathrm{~g} / 100 \mathrm{~mL}$ (the concentration of chlorhexidine in this product is much lower than $7.1 \%$ CHX for umbilical cord care). 


\section{WILLINGNESS AND RATIONALE TO USE CHX}

The use of 7.1\% chlorhexidine for umbilical cord care is not widely known by community members in Togo. Most of the FGD participants were unaware of this novel cord care product. Some participants from three different health centers (Centre Hospitalier Universitaire Sylvanus Olympio, Centre Médico Scolaire de Bago, Centre Hospitalier Préfectoral de Vogan) had seen the CHX cord care product. One person at Centre Hospitalier Régional de Dapaong reported having used a chlorhexidine liquid product for personal hygiene. The CHX cord care product was available at only 1 of the 13 facilities visited (Agoé Elavagnon health center).

FGD participants reported high hypothetical acceptability of the product due to its aesthetic presentation, ease of use, ease of storage, and provider recommendation, as below:

"For example, you buy the product and it is already there in the tube, ready to be used. It's better instead of going into the bush, looking for the leaves to come and burn, heat the oil before putting in it." [FGD 12]

"You can take it on you, put it in your bag, walk around freely, while the oil there can pour into your bag, but it's protected." [FGD 4]

"First of all, I see that it is well protected compared to the oil that we use. The oil that we use, it's true that it also has its role that it plays, but first the pots in which we try to extract the oil, we leave them, there is the dust that can fall there in. Since it is a wound, if you do not know how to use it properly, or if you do not know how to protect it well, it can infect the place. So, this was prepared maybe in very clean conditions, maybe that's the advantage." [FGD 2]

Actual use was contingent on positive product performance in terms of time to heal the wound, fast cord separation, and absence of pain in the infant. Finally, the FGD participants thought the name of the CHX product (Chlorxy-G) was difficult to remember and were concerned about an affordable price.

"In my opinion, nothing can prevent us from using it, but only if the price is at our level, we can buy it easily. Because we do not know how much they can sell us that." [FGD 9]

"Apart from the price, if you have not memorized the name, and without the midwife's prescription, you cannot buy it. " [FGD 13]

"And there are times that someone may want to buy this. But when you come home, with the child, with life and the elderly, they will say leave it, that is what we used for the kids, what-what! So, there is that, you can have the will, the desire. But hey, there is also that, if you are with them, you are obliged to leave, or either to pass with it in secret if you can. " [FGD 13]

"Me, for example, if I put this on, I see that by putting this the child is crying, while the other child is not crying, I will leave!" [FGD 4]

"Or if you use that, and the umbilical cord doesn't fall off quickly, you might be discouraged from using it."
| [FGD 2]

Almost $70 \%$ of the providers were aware of CHX and all of them were supportive of its use. The providers were aware that the CHX product should be applied to the cord stump from the tip to the base once per day. Most of the providers agreed that the use of CHX could reduce neonatal death, avoid umbilical cord tetanus/infection, and that it will not stain the infant's clothes. They also believed that the use of CHX gel would make the umbilical cord dry more quickly.

\section{PREFERRED PRODUCT PRICING AND SOURCE}

The FGD participants identified the range of preferred product pricing to be from zero (i.e., no charge) to FCFA 10,000. Even though the participants were aware of their very low purchasing power, they agreed that they could buy the gel at a price between 1,000 FCFA and 2,000 FCFA, because it was for the well-being of their babies. When the FGD participants were asked about their reaction to a price point of FCFA 800, they responded favorably, as noted:

"I would say that if this product is 800 it is a good price. Because generally 800 there, almost everyone can get that. In addition, it is a pharmaceutical product, often creams like that, when we say pharmaceutical product you are already at 1,500-2,000 what-what. But here you are told that you are below 1,000 francs, so it's good." [FGD 13]

"Me personally, considering the packaging and the tube, I did not expect a price like that, I thought it would be around 4,000 and something." [FGD 10]

"With 800 it is good, it's affordable. With 800 we will have $80 \%$ of people who will buy." [FGD 13]

The FGD participants felt that other community members would be able to afford the FCFA 500 price point. A common viewpoint was that the price should be around FCFA 500 for all community members since that is the price of Vaseline petroleum jelly, which is also used for cord care.

Providers were quite aligned with the pricing suggested by the FGD participants (Figure 2), as they identified the range of preferred product pricing to be from FCFA 500$1,500(\mathrm{M}=760, \mathrm{SD}=334.74)$. The majority of providers suggested a price between FCFA 500-800, keeping the purchasing power of the population in mind (mode $=500$, median=550). The minority of providers suggested a price between FCFA 900-1,500 to showcase the high quality of the product. A majority (61\%) of providers felt a price point of FCFA 800 would be an appropriate (59\%) or very good (5\%) value for the product, and $59 \%$ of providers felt that pregnant women and new mothers would find the FCFA 800 price point acceptable. Further, $84 \%$ of providers felt a price point of FCFA 600 would be an appropriate $(68 \%)$ or very good (16\%) value for the product, and $83 \%$ of providers felt that pregnant women and new mothers would find the FCFA 800 price point acceptable (Table 5).

The FGD participants wanted the CHX product to be available for sale in pharmacies, hospitals, and health centers. They felt that they would be more likely to obtain counterfeit products in the boutiques, shops, area around the markets and health centers, and markets, so they did 
Table 5. Provider viewpoints on demand for $\mathrm{CHX}(\mathrm{n}=38)$

\begin{tabular}{|c|c|c|}
\hline$\%(n)$ & $\%(n)$ & $\%(n)$ \\
\hline \multicolumn{3}{|c|}{ Give pregnant women a list of items they need to bring to their birth? } \\
\hline No & Yes & \\
\hline $97(37)$ & $3(1)$ & \\
\hline \multicolumn{3}{|c|}{ Aware of a product called chlorhexidine for umbilical cord care? } \\
\hline No & Yes & \\
\hline $34(13)$ & $66(25)$ & \\
\hline \multicolumn{3}{|c|}{ What is the best time for women to obtain this product? } \\
\hline During antenatal care & Before delivery & At time of delivery \\
\hline $79(30)$ & $21(8)$ & 0 \\
\hline \multicolumn{3}{|c|}{ Affordable price for mothers/families to pay for this product?*** } \\
\hline $\begin{array}{l}\text { Mean } \\
\text { CFA } 760\end{array}$ & $\begin{array}{l}\text { Mode } \\
\text { CFA } 500\end{array}$ & $\begin{array}{l}\text { Median } \\
\text { CFA } 550\end{array}$ \\
\hline \multicolumn{3}{|c|}{$\begin{array}{l}\text { If the price of this product to mothers is CFA } 800 \text {, would you consider that price to be:* } \\
\mathrm{N}=37 \text { ) }\end{array}$} \\
\hline Expensive, poor value & About right, appropriate value & Lower than expected, very good value \\
\hline $35(13)$ & $59(22)$ & $5(2)$ \\
\hline \multicolumn{3}{|c|}{ Would mothers be willing to buy one tube of product for CFA $800 ?^{*} \mathrm{~N}=37$} \\
\hline No & Yes & \\
\hline $41(15)$ & $59(22)$ & \\
\hline \multicolumn{3}{|c|}{$\begin{array}{l}\text { If the price of this product to mothers is CFA } 600 \text {, would you consider that price to be:* } \\
n=37\end{array}$} \\
\hline Expensive, poor value & About right, appropriate value & Lower than expected, very good value \\
\hline $16(6)$ & $68(25)$ & $16(6)$ \\
\hline \multicolumn{3}{|c|}{ Would mothers be willing to buy one tube of product for CFA $600 ?^{* *} \mathrm{~N}=36$} \\
\hline No & Yes & \\
\hline $17(6)$ & $83(30)$ & \\
\hline
\end{tabular}

*missing data $(\mathrm{n}=37)$; ** missing data $(\mathrm{n}=36)$

**** Four respondents did not provide a precise number estimate and two respondents do not reply to this question.

not want to purchase the CHX product in these places. In addition to the pharmacies (public and private), hospitals, and health centers, the providers thought that the product should be sold in the delivery room and as part of the clean delivery kit.

\section{DISCUSSION}

This study provided contextual understanding of the potential drivers of CHX uptake in Togo. Currently, there is limited availability of the CHX product in the private sector, mostly in or around the capital city of Lomé. Most of the FGD participants and about one-third of the providers in our study were unaware of $7.1 \%$ chlorhexidine for umbilical cord care despite a revision in the national newborn policy to include this new practice in 2017. The product appeared to be largely unavailable in facilities, which contributed to the lack of demand. Because CHX availability was very limited in the public sector, providers recommended alcohol or other skin disinfectants for cord cleaning.

Setting the price of the CHX product at a point that is

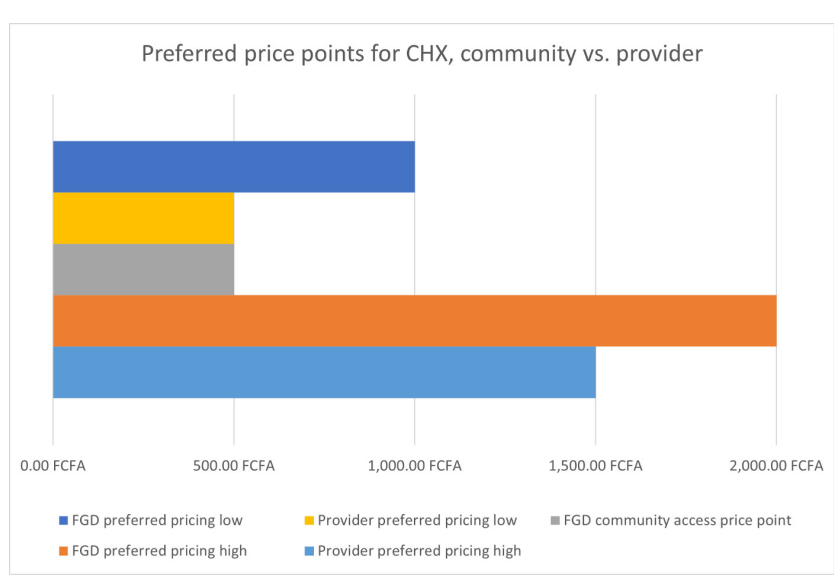

Figure 2. Preferred price points for CHX.

affordable to families who are birthing in health centers or at home is a critical aspect to building demand. In Nigeria and Kenya, pricing CHX slightly lower than the most-used umbilical cord care product, methylated spirits, was sug- 
gested as the optimal pricing strategy. ${ }^{8}$ In Togo, a price point of FCFA 500 could be affordable for most families although more thorough value-based willingness-to-pay research would need to be conducted to confirm the actual price. For example, in Bangladesh, a household-based contingent valuation method study conducted among 1,717 eligible couples identified a CHX product price point that was within reach of all families. ${ }^{9}$ Likewise, the perceived benefits of using CHX for umbilical cord care must outweigh traditional cord care practices. Participants in our study reported purchasing a variety of substances for cord care including Vaseline and Close-up toothpaste. Given that FGD participants in our study estimated the cost of items they usually purchased to prepare for a birth to be between FCFA $35,000-50,000$, purchasing CHX at CFCA 500 (10-15\% of this overall cost) seems feasible.

Setting the optimal price point will contribute to more effective demand generation. In Togo, demand could be created by having providers recommend CHX use and positioning it as an essential item for families to procure during childbirth preparations. Including CHX in clean delivery kits and making their provision a mandatory item for childbirth preparation could also increase demand greatly. Four countries (Bangladesh, Ethiopia, Nepal, and Nigeria) ${ }^{10-17}$ that are leading the way globally in the introduction and scale of CHX for umbilical cord care are integrating CHX as part of the essential newborn care package of services. In these countries, however, the CHX product is procured as part of the government public-sector budget allocation. In Togo, government budget allocation for this newborn commodity to not forthcoming. Thus, linkage with the privatesector supplier is of utmost importance.

Figure 3 presents a model of how demand generation can support improved access to a CHX product, based on the results of this study. In this model, public sector provision of CHX is less stable due to administrative and budgetary procedures related to the government tendering process. Therefore, the manufacturer must make product available at private sector pharmacies through distributors and/or sales detailers and also invest in product promotion and training for sales agents. On the public sector side, demand can be generated directly by the provider by offering pregnant women and their families a list of birth preparedness items and a prescription for CHX. Ideally the use of CHX as part of essential newborn care would be supported via social behavioral change communication (SBCC) as well.

The law of supply and demand determines a price equilibrium at which demand will be sustained. Creating easy access to the CHX product can be implemented by offering the product for sale at both public-sector and private-sector pharmacies and facilities in all geographies. The current distributor for the CHX product in Togo would benefit from reintroducing the product dossier for market authorization, indicating the February 2020 prequalification of its product by the West African Health Organization (WAHO), as a way to support improved product access and demand generation. The prequalification of the CHX product by WAHO is part of a regional regulatory harmonization effort that will facilitate market authorization in the 15 countries in the Economic Community of West African States region.

Both FGD participants and providers viewed the effect of
CHX use on time to cord separation as a key determinant of product uptake. When compared to current cord care practices, CHX use has been associated with longer time to cord separation in Nepal, Bangladesh, Turkey, India, Iran, and Uganda. ${ }^{18-22}$ In Kenya, however, mothers reported "fast healing of the cord" when CHX was used. ${ }^{23}$ Managing this expectation of shorter time to cord separation will be a key driver for uptake of CHX in Togo. It will also be important to assure proper use of the CHX product to avoid situations where untrained providers or family members mistakenly apply it to the eyes of a newborn, which can cause serious injury. ${ }^{24}$

In addition, FGD respondents noted that the name of the current CHX product is difficult to remember. An exploration into different branding could facilitate product uptake as well as help potential users distinguish between legitimate and counterfeit products.

This study was limited by its small sample size and convenience sampling, which may have contributed to a possible bias in data gathering or sampling error. Of note is that the FGD participants were women who go to antenatal care consultations and/or birthed in health centers. These women most likely come from households that could easily support the purchase of a clean delivery kit and CHX. In particular, the suggested price point of FCFA 500 for the CHX product has not been vetted by women who birth at home and may be less likely to be able to afford to purchase a clean delivery kit and/or a CHX product. In addition, this type of study can identify trends in the descriptive data only and caution should be used when drawing generalized conclusions from this dataset.

\section{ACKNOWLEDGEMENTS}

The authors would like to acknowledge our data collection team who worked diligently to collect data throughout Togo, namely Sibi Louise MAHE, ADEDJE Essivie Wolali, NICOE Adevi Chantal, DOKOUNON Yawovi Edo. In addition, the authors would like to thank Mutsumi Metzler for her thoughtful comments from a commercialization perspective and Robbie Adams for assistance in manuscript preparation.

\section{DISCLAIMER}

The views expressed in this article are those of the authors and not an official position of PATH or its funders.

\section{FUNDING}

This study was conducted with generous support from the Bill and Melinda Gates Foundation grant number INV-008987 / OPP1180469 entitled Francophone West Africa (OP) Regional Hub for RMNCH Continuum Delivery of PostPartum Family Planning, Nutrition and Essential Newborn Package, which was led by IntraHealth International. The views expressed in this article are solely the views of the authors and do not necessarily reflect the views of the funding or implementing agencies. 


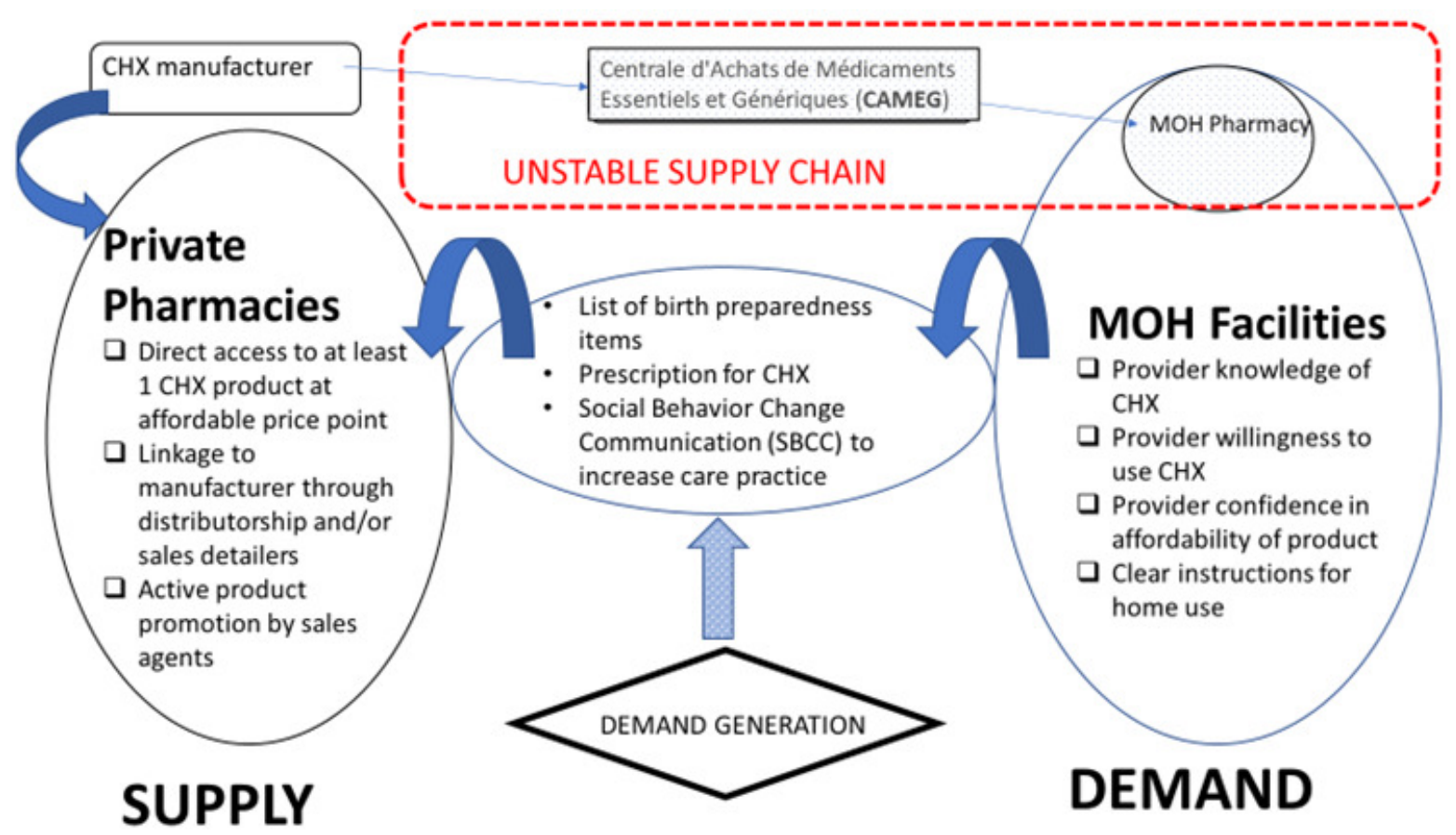

Figure 3. Model for demand generation of CHX.

\section{AUTHORSHIP CONTRIBUTIONS}

PSC conceived of the design, provided overall direction, developed the protocol and data collection forms, performed analysis and drafted the manuscript. All other authors reviewed the protocol and data collection instruments and provided overall direction for data collection at country level. All authors reviewed and approved the final manuscript.

\section{COMPETING INTERESTS}

All authors other than PSC declare no competing interests.
PSC led the global Chlorhexidine Working Group from 2012-17 as part of her scope of work at PATH.

\section{CORRESPONDENCE TO:}

Patricia S. Coffey, PhD, MPH, PATH, 2201 Westlake Ave, Suite 200, Seattle, WA 98211, 206-302-4704, pcoffey@path.org

Submitted: June 18, 2020 GMT, Accepted: December 18, 2020 GMT 


\section{REFERENCES}

1. Healthy Newborn Network. Chlorhexidine for Umbilical Cord Care. London, UK: Save the Children, Saving Newborn Lives program, Health Newborn Network https://www.healthynewbornnetwork.org/iss ue/chlorhexidine-for-umbilical-cord-care/.

2. Arifeen SE, Mullany LC, Shah R, et al. The effect of cord cleansing with chlorhexidine on neonatal mortality in rural Bangladesh: A community-based, cluster-randomised trial. The Lancet. 2012;379(9820):1022-1028. doi:10.1016/s0140-6736(1 1) $61848-5$

3. Hodgins S, Thapa K, Khanal L, et al. Chlorhexidine gel versus aqueous for preventive use on umbilical stump: A randomized noninferiority trial. The Pediatric Infectious Disease Journal. 2010;29(11):999-1003. doi:10.1097/inf.0b013e3181e7 $\underline{0 \mathrm{c} 59}$

4. Imdad A, Mullany LC, Baqui AH, et al. The effect of umbilical cord cleansing with chlorhexidine on omphalitis and neonatal mortality in community settings in developing countries: A meta-analysis. BMC Public Health. 2013;13(Suppl 3):S15. doi:10.118 6/1471-2458-13-s3-s15

5. LeFevre AE, Shillcutt SD, Waters HR, et al. Economic evaluation of neonatal care packages in a cluster-randomized controlled trial in Sylhet, Bangladesh. Bull World Health Organ. 2013;91(10):736-745. doi:10.2471/blt.12.117127

6. Mullany LC, Darmstadt GL, Khatry SK, et al. Topical applications of chlorhexidine to the umbilical cord for prevention of omphalitis and neonatal mortality in southern Nepal: A community-based, clusterrandomised trial. The Lancet. 2006;367(9514):910-918. doi:10.1016/s0140-6736(0 6)68381-5

7. Soofi S, Cousens S, Imdad A, Bhutto N, Ali N, Bhutta ZA. Topical application of chlorhexidine to neonatal umbilical cords for prevention of omphalitis and neonatal mortality in a rural district of Pakistan: A community-based, cluster-randomised trial. The Lancet. 2012;379(9820):1029-1036. doi:10.1016/s014 $\underline{0-6736(11) 61877-1}$

8. Metzler M, Coffey PS. Using consumer data to inform marketing strategies for chlorhexidine for umbilical cord care programming in Kenya and Nigeria. Social Marketing Quarterly. 2018;24(4):235-248. doi:10.1177/1524500418797296
9. Coffey PS, Metzler M, Islam Z, Koehlmoos TP. Willingness to pay for a $4 \%$ chlorhexidine (7.1\% chlorhexidine digluconate) product for umbilical cord care in rural Bangladesh: A contingency valuation study. BMC Int Health Hum Rights. 2013;13(1):article 44. doi:10.1186/1472-698x-13-44

10. Maternal and Child Health Integrated Program (MCHIP). Supporting the Scale-Up of Universal Cord Stump Cleaning in Bangladesh: Successes and Challenges. Washington, DC, USA and Bangladesh: US Agency for International Development and MCHIP; 2018. https://www.mchip.net/technical-reso urce/supporting-the-scale-up-of-universal-cord-stu mp-cleansing-in-bangladesh-successes-and-challeng es/.

11. Callaghan-Koru JA, Khan M, Islam M, et al. Implementation outcomes of the national scale up of chlorhexidine cord cleansing in Bangladesh's public health system. Journal of Global Health. 2019;9(2):020410. doi:10.7189/jogh.09.020410

12. Tadesse Y, Abdella YM, Tadesse Y, et al. Integrating chlorhexidine for cord care into community based newborn care in Ethiopia. Ethiopian Medical Journal. 2019;Supp. 3. https://ww w.emjema.org/index.php/EMJ/article/view/1395.

13. Lamichhane B, Khanal L, Shrestha PR, Dawson P, Singh S. Nepal scale up chlorhexidine as part of essential newborn care: Country experience. J Nepal Health Res Council. 2018;16(3):359-361. doi:10.3126/ inhrc.v16i3.21443

14. Oyloe P, Khanal L, Hodgins S, Pradhan ST, Dawson P. Innovative product development partnership reduced neonatal mortality in Nepal through improved umbilical cord care. Health Affairs. 2017;36(11):1973-1978. doi:10.1377/hlthaff.2017.054 8

15. John Snow, Inc. (JSI) Research and Training Institute, Inc./Chlorhexidine Navi Care Program. Scaling-Up the Use of Chlorhexidine for Umbilical Cord Care: Nepal's Experience. Healthy Newborn Network website. November 2017. https://www.health ynewbornnetwork.org/resource/scaling-up-the-use-o f-chlorhexidine-for-umbilical-cord-care-nepals-exper ience/.

16. Goldman TR. To reduce neonatal mortality, Nigeria is taking a simple treatment nationwide. Health Affairs. 2017;36(11):1979-1986. doi:10.1377/h lthaff.2017.1230 
17. Nigeria Federal Ministry of Health. National Strategy for Scale-Up of Chlorhexidine in Nigeria. Abuja, Nigeria: Federal Ministry of Health; 2016. http s://www.healthynewbornnetwork.org/hnn-content/u ploads/NATIONAL-STRATEGY-FOR-SCALE-UP-OF-C HX-IN-NIGERIA-FINAL-002.pdf.

18. Mullany LC, Arifeen SE, Khatry SK, et al. Impact of Chlorhexidine Cord Cleansing on Mortality, Omphalitis and Cord Separation Time Among Facility-Born Babies in Nepal and Bangladesh. The Pediatric Infectious Disease Journal.

2017;36(10):1011-1013. doi:10.1097/inf.00000000000 $\underline{01617}$

19. Ozdemir H, Bilgen H, Topuzoglu A, et al. Impact of different antiseptics on umbilical cord colonization and cord separation time. J Infect Dev Ctries. 2017;11(02):152-157. doi:10.3855/jidc.7224

20. Abbaszadeh F, Hajizadeh Z, Jahangiri M. Comparing the impact of topical application of human milk and chlorhexidine on cord separation time in newborns. Pak J Med Sci. 2016;32(1):239-243. doi:10.12669/pims.321.8223
21. Mukunya D, Haaland MES, Tumwine JK, et al. "We shall count it as a part of Kyogero": Acceptability and considerations for scale up of single dose chlorhexidine for umbilical cord care in Central Uganda. BMC Pregnancy Childbirth. 2018;18(1):476. doi:10.1186/s12884-018-2116-3

22. Lyngdoh D, Kaur S, Kumar P, Gautam V, Ghai S. Effect of topical application of human breast milk versus $4 \%$ chlorhexidine versus dry cord care on bacterial colonization and clinical outcomes of umbilical cord in preterm newborns. J Clin Neonatol. 2018;7(1):25-30. doi:10.4103/jen.jen 9117

23. Muriuki A, Obare F, Ayieko B, Matanda D, Sisimwo $\mathrm{K}$, Mdawida B. Health care providers' perspectives regarding the use of chlorhexidine gel for cord care in neonates in rural Kenya: Implications for scale-up. BMC Health Serv Res. 2017;17(1):305. doi:10.1186/s1 2913-017-2262-8

24. World Health Organization. Information Exchange System Alert No. 133: Chlorhexidine 7,1\% Digluconate (CHX) Aqueous Solution or Gel (10ml) Reports of Serious Eye Injury Due to Errors in Administration. Geneva, Switzerland: The World Health Organization; 2019. 